\title{
Understanding the Broader Sexual and Reproductive Health Needs of Female Sex Workers In Dhaka, Bangladesh
}

\section{By Karen R. Katz, Misti McDowell, Mackenzie Green, Shamim Jahan, Laura Johnson and Mario Chen}

Karen R. Katz is deputy director of health services research, and Mario Chen is associate director of biostatistics,

FHI 360, Durham,

NC, USA. At the time this research was conducted, Mackenzie Green was research associate III, FHI

360. Misti McDowell is country director,

Ethiopia, FHI 360, Addis Ababa. Shamim Jahan is chief of party, SHIKHA Project, FHI 360, Dhaka, Bangladesh. Laura Johnson is senior researcher, Westat, Durham. CONTEXT: Little is known about the sexual and reproductive health care needs of female sex workers in Dhaka,
Bangladesh.

\begin{abstract}
METHODS: Survey data were collected from 354 hotel-based and 323 street-based female sex workers using a venue-based stratified cluster sampling approach. In addition, in-depth interviews were conducted with 20 female sex workers recruited from drop-in centers. We calculated unmet need for family planning and examined fertility desires, use of condoms and other contraceptive methods, experiences with gender-based violence, sexual and reproductive health service needs, and preferences on where to receive services.
\end{abstract}

RESULTS: The prevalence of unmet need was 25\% among hotel-based female sex workers and $36 \%$ among streetbased female sex workers. Almost all participants reported having used condoms in the past 30 days, and $44 \%$ of hotel-based sex workers and $30 \%$ of street-based sex workers reported dual method use during that period. Condom use was inconsistent, however, and condom breakage and nonuse for extra money were common. Many women reported experiencing gender-based violence. Sexual and reproductive health services had been obtained by $64 \%$ of hotel-based and $89 \%$ of street-based sex workers in the past six months; drop-in centers were their preferred site for receiving health services.

CONCLUSIONS: Female sex workers in Dhaka need family planning and other sexual and reproductive health services and prefer receiving them from drop-in centers.

International Perspectives on Sexual and Reproductive Health, 2015, 41(4):182-190, doi: 10.1363/4118215

Female sex workers have a broad range of sexual and reproductive health needs, which mounting evidence indicates are not being met. ${ }^{1-4}$ Stigma and discrimination, as well as policy and access challenges, discourage female sex workers from using traditional clinic-based services, which has led to alternative models of service delivery that specifically target this population. ${ }^{2,5}$ These services, however, generally focus on prevention, care and treatment of HIV and other STIs; this means that many of female sex workers' reproductive health needs, including family planning, are frequently neglected.

Although HIV programs promote condom use as a means of preventing STIs, prevention of unintended pregnancy often is not a primary concern., ${ }^{2,6}$ If used consistently, condoms protect against both HIV and pregnancy; however, despite reports of widespread condom use among female sex workers, evidence indicates that such use is inconsistent. Female sex workers may use condoms inconsistently because they lack the autonomy to insist on condom use with husbands, boyfriends or other steady partners, agree to have condomless sex with clients who will pay extra, are unable to negotiate condom use with clients and or are forced to have sex. ${ }^{6-11}$

Using condoms inconsistently, rather than every time, increases the risk not only of acquiring an STI, but also of pregnancy if a second contraceptive method is not used.
The lifetime prevalence of abortion among female sex workers in Asia and Africa ranges from 22\% to 86\%, ${ }^{6-9,12-14}$ suggesting that sex workers' pregnancies frequently are unintended. These high rates of abortion should not be surprising, considering the burdens that pregnancy may pose to such women. ${ }^{13,15}$ Indeed, the levels of contraceptive use reported by female sex workers in various countries indicate a strong desire to avoid unintended pregnancy. ${ }^{1,8,9,14}$ Few studies have calculated the unmet need for contraception in this population; estimates have ranged from $4 \%$ to $29 \%,{ }^{9,10,14}$ but these rates generally are not comparable across studies because the methods used for calculating unmet need have varied.

\section{Bangladeshi Context}

Earning a living as a sex worker is legal in Bangladesh. However, municipal ordinances that prohibit soliciting in public or creating a public nuisance can result in the harassment, detainment or arrest of sex workers. ${ }^{16}$ The majority of sex workers in Bangladesh are either hotel- or street-based, but some work in brothels or residences. Little is known about their family planning needs or experiences, although behavioral survey data collected in Dhaka in 2006-2007 revealed that levels of consistent condom use among female sex workers were low, while rates of condom breakage were high and experiences of gender- 
based violence were common. ${ }^{17}$ About one-third reported having been raped in the past year, and $60 \%$ of street-based and $40 \%$ of hotel-based sex workers reported having ever been raped or beaten. The prevalence of condom use differed between the two groups, as $81 \%$ of street-based sex workers reported condom use at last sex, compared with $40 \%$ of their hotel-based counterparts. A qualitative study highlighted discrepancies between reported and actual condom use among female sex workers at a brothel in Bangladesh: While many indicated that they used condoms, they also acknowledged that they sometimes agreed not to use them. ${ }^{18}$ Competition for clients was one reason cited, especially by older women, who reported that they sometimes agreed to requests for condomless sex to compete with their younger counterparts. Overall, these data indicate that Bangladeshi female sex workers do not use condoms consistently, which may place them at high risk for pregnancy, and that they have a need for other sexual and reproductive health services, such as those for victims of gender-based violence.

A 2009 study in Bangladesh showed that while brothelbased female sex workers were largely satisfied with the HIV services provided by nongovernmental organizations (NGOs), their main criticism was that the services available were limited. ${ }^{19}$ Several NGOs serving female sex workers in Dhaka have addressed this concern by broadening the services they provide; in addition to STI prevention, care and treatment, they provide tuberculosis care and other general health care services. Moreover, some not only distribute condoms, but also provide-through drop-in centers and peer educator outreach-family planning information and short-term contraceptive methods (such as the pill and the injectable), as well as referrals for long-acting methods. ${ }^{20}$ To further expand access to services, drop-in centers also link sex workers to other NGOs and private providers, such as the Smiling Sun Franchise Project and Blue Star providers. These programs have been hindered, however, by policies that restrict access to contraceptive methods: Short-term methods are offered only to married women, and until recently certain long-term and permanent methods were offered only to married women with at least one child. ${ }^{21}$

In this study, we sought to obtain greater understanding of the discrepancy between the reports of widespread condom use and the high rates of abortion documented among female sex workers in other studies, as well as to determine if the broader sexual and reproductive health needs of these women are being met (i.e., beyond the prevention, care and treatment of HIV and other STIs). Working with local NGO partners that provide services to female sex workers, we conducted a formative assessment among hotel-based and street-based female sex workers in Dhaka to calculate each group's unmet need for contraception, identify other sexual and reproductive health services needed by these women and determine their preferences for where to receive services. Our ultimate goal was to inform the development of interventions to better address female sex workers' sexual and reproductive health care needs.

\section{METHODS \\ Study Design and Sample}

We conducted a mixed-method study in collaboration with two local NGOs that provide services to female sex workers: the Bangladesh Women's Health Coalition (BWHC) and Durjoy Nari Shangha (DNS). Between May and July 2011, we collected survey data at both street and hotel sites where female sex workers are based. In addition, we conducted in-depth interviews in July 2011 at drop-in centers operated by the NGOs. No compensation was provided to participants. The study was approved by the Protection of Human Subjects Committee at FHI 360 and the Bangladesh Medical Research Council in Bangladesh.

We recruited female sex workers for the survey using a venue-based stratified cluster sampling approach. A female sex worker was defined as any woman who reported having received money or goods in exchange for sexual services as a source of income in the last six months. All female sex workers aged 18-35 who were not pregnant were eligible to participate. Hotel-based female sex workers are normally contacted by clients at hotels that operate specifically for sex work, whereas street-based workers are typically contacted by clients on the street or in other public places, such as parks or transportation hubs. BWHC and DNS provided complete lists of the hotel and street sites they served; the list included 47 hotel sites with a range of five to 50 female sex workers and 42 street sites where 10-122 female sex workers were based. Each list was randomly ordered, and the first 30 hotels and 25 street sites were selected for inclusion. If a hotel site was closed, if venue managers were unwilling to participate or if more interviews were needed, then the study team proceeded to the next site on the list. Because of a large number of closures, only 22 hotels on the list remained open; all were included in the study. To help ensure the safety of interviewers, data collection took place during the day at the hotels and during the early evening on the streets. Staff from BWHC or DNS facilitated obtaining permission at each site to conduct interviews. In each location, all female sex workers who were present during a five-hour period were enumerated, approached for an interview and, if eligible, were interviewed in the Bangla language after providing oral informed consent.

The targeted sample size for each type of female sex worker was 400 . This number was sufficient to obtain an estimate of the prevalence of unmet need for contraception within five percentage points with a 95\% confidence interval. Given the lack of data to inform sample size calculations, we assumed a 50\% base estimate, which would require a larger sample size than would other base estimates, and an intraclass correlation of 3\% to account for clustering effects due to the selection of multiple female sex workers within sites. Calculations were adjusted for finite population size, since the sample is restricted to the 
population covered in the mapping activities.

Recruitment for in-depth interviews was done at two drop-in centers in Dhaka, one run by DNS that targets street-based female sex workers and another run by BWHC that targets hotel-based female sex workers. Dropin centers were used because they provided a site where lengthy interviews could be conducted in private at a time when the women would not be working. Study staff and program staff worked together to recruit sex workers who were seeking HIV services on the days of data collection; recruitment took place during mornings and afternoons. The age range for recruitment was identical to that for the survey, but pregnant sex workers were eligible to participate because they could provide insight regarding the need for and access to family planning services. Data collectors, who were specially trained in qualitative interview techniques, screened and recruited potential participants. Recruitment was designed to obtain a sample diverse in parity (0-1 child vs. two or more children); we set targets of five to eight participants in each stratum for hotel-based female sex workers and for street-based female sex workers. Data collectors approached either every female sex worker present or every other one, depending on the number of women at the clinic on that particular day. If the sex worker was eligible and the target had not yet been met, the data collector obtained informed consent and asked the woman for permission to audiotape the interview. No identifying information was kept on the tapes or the transcripts. Interviews were conducted in Bangla in a private room at the drop-in center. We set a target of 20-32 indepth interviews, to account for data saturation and logistical considerations, and conducted a total of 20.

The survey collected information on social and demographic characteristics, knowledge and use of family planning methods, details about condom use, knowledge of and actual sources of contraceptive methods, fertility desires and use of reproductive health services. In-depth interviews followed a semistructured guide to obtain further insights and context on survey topics. Specifically, the interviews explored sex workers' attitudes about pregnancy and family planning use, the constraints on their use of methods, the types of reproductive health services they required and the best way to provide these services to maximize their access. Gender-based barriers were also explored

\section{Analysis}

We used descriptive analyses to summarize background characteristics, contraceptive use and health care experiences. Hotel- and street-based female sex workers were described separately, since their experiences and needs may differ. The primary study outcome was unmet need for family planning. Sex workers were categorized as having unmet need if they did not want to become pregnant in the next 12 months and were not using a modern method of contraception. Although other studies often use a longer time frame in unmet need calculations (e.g., not wanting a birth within two years), we used a more stringent definition because of the implications of pregnancy for our study population and these women's strong desire to avoid unwanted pregnancies. Contraceptive methods classified as modern were oral contraceptive pills, implants, injectables, IUDs, emergency contraceptive pills, female sterilization and, if used consistently, condoms. Women were considered to be using condoms consistently if they had used condoms during both their last five sex acts with clients and their last five acts with emotional partners (husbands, boyfriends or other steady partners). For women without emotional partners, classification of condom use consistency was based solely on sex acts with clients. Our condom measure was designed to provide a more accurate picture of condom use than do other measures commonly used in the literature, such as condom use at last sex.

Survey data were analyzed using Stata 13.0. For both types of female sex worker, we calculated 95\% confidence intervals for estimates of the proportion with unmet need. Standard errors for the confidence interval estimates were adjusted for clustering effects of the sampling location and stratified by type of sex worker. Qualitative data were transcribed and translated into English, and thematic coding and analysis were carried out in QSR NVivo 9. The study team developed a list of a priori codes (such as contraceptive use, impact of pregnancy on work and home life, and patterns of condom use) based on the interview guide; additional codes were created to capture emerging themes (such as concerns about sex work). We applied these codes to all transcripts, ran reports for each code, and created memos to describe themes and subthemes that emerged. Selected findings and quotations from in-depth interviews are reported to provide additional context to the survey findings.

\section{RESULTS}

\section{Sample Characteristics}

At both types of sites, 96\% of eligible women completed the survey, yielding a sample consisting of 354 female sex workers from 22 hotels and 323 female sex workers from 25 street sites. Both groups were relatively young, on average in their early to mid-20s; the majority had little or no education, and most had an emotional partner (Table 1, page 185). Hotel-based sex workers averaged 22 clients per day; street-based sex workers, six clients.

The majority of women in both groups had experienced at least one pregnancy, and approximately $40 \%$ in each group reported having had at least one abortion or menstrual regulation.* Although most study participants were relatively young, more than $80 \%$ of women in the two groups did not want to get pregnant within the next year,

*Menstrual regulation uses manual vacuum aspiration to evacuate the uterus of a woman after a missed period to ensure a state of nonpreg nancy. In Bangladesh, menstrual regulation is legal for up to 10 weeks after a missed period (source: Johnston HB et al., Health system costs of menstrual regulation and care for abortion complications in Bangladesh, International Perspectives on Sexual and Reproductive Health, 2010, 36(4):197-204). 
and more than half of the hotel-based sex workers and two-thirds of the street-based sex workers did not want another child ever. In-depth interview respondents explained that they believed pregnancy would have a negative impact on their work and on their life in general. They expressed concerns that having a child would damage their reputation, that the baby would not have an identity and that they did not want a child from sex work. They also worried that their earnings would be affected and that they could not care for a baby. Only one interview respondent said that she wanted a baby and that the impact of a pregnancy would be positive.

\section{Contraceptive Use and Unmet Need}

Although the majority of participants did not want to get pregnant within the next year, and nearly all reported use of a contraceptive method in the past 30 days, unmet need for contraception was fairly high-25\% among hotel-based sex workers and 36\% among street-based sex workers (Table 2). Contraceptive use was largely driven by condom use, as at least $90 \%$ of women in each group had used condoms in the past 30 days. The pill and the injectable were the other most commonly used methods.

Dual method use was reported by $44 \%$ of hotel-based sex workers and 30\% of street-based sex workers; only $3-5 \%$ were using a contraceptive method but were not using condoms. In in-depth interviews, half of the participants explained that contraceptive method use did not affect their use of condoms, and none said that use of other methods influenced their condom use; they relied on condoms to prevent STIs, including HIV, and on other contraceptive methods to prevent pregnancy. As a 28-year-old street-based sex worker explained, "contraceptive methods do not protect us from sexual disease. [They] only prevent us from getting pregnant. Condoms protect [against] sexual disease."

Although nearly all respondents had used condoms in

\begin{tabular}{|lll|}
$\begin{array}{l}\text { TABLE 1. Characteristics of female sex workers, by location } \\
\text { of sex work, Dhaka, Bangladesh, 2011 }\end{array}$ & \\
Characteristic & $\begin{array}{l}\text { Hotel } \\
\text { (N=354) }\end{array}$ & $\begin{array}{l}\text { Street } \\
\text { (N=323) }\end{array}$ \\
& & \\
\hline Mean age (yrs.) & 22.0 & 25.7 \\
Yrs. of education & & \\
0 & 33 & 53 \\
$1-6$ & 31 & 36 \\
$7-13$ & 36 & 11 \\
Has emotional partner & 64 & 75 \\
Mean no. of clients per day & 21.5 & 5.6 \\
Ever pregnant & 66 & 84 \\
Ever had abortion/menstrual regulation & 38 & 41 \\
Has $\geq \mathbf{1}$ living child & 42 & 67 \\
Mean no. of living children* & 1.3 & 1.6 \\
Fertility desirest & & \\
Does not want a child & 54 & 66 \\
Wants pregnancy in $>1$ year & 31 & 20 \\
Wants pregnancy in $\leq 1$ year & 5 & 11 \\
Wants child but unsure when & 10 & 3 \\
& & \\
\hline *Am & &
\end{tabular}

*Among those with living children ( 148 hotel-based and 217 street-based sex workers). †Excludes one hotel-based sex worker who did not respond to this item. Notes: All values are percentages unless otherwise indicated.
TABLE 2. Selected measures of contraceptive use among female sex workers, by location of sex work

\begin{tabular}{|lll|} 
Measure & $\begin{array}{l}\text { Hotel } \\
(\mathrm{N}=354)\end{array}$ & $\begin{array}{l}\text { Street } \\
(\mathrm{N}=323)\end{array}$ \\
\hline \% with unmet need $\mathbf{9 5 \%}$ Cl) & $25(20-30)$ & $36(30-41)$ \\
\% used modern contraceptives in past 30 days* & & \\
Any & 98 & 95 \\
Condoms & 95 & 90 \\
Pill & 37 & 13 \\
Injectable & 8 & 13 \\
Other & 2 & 7 \\
Dual methods & 44 & 30 \\
Only noncondom methods & 3 & 5 \\
Condoms only & 51 & 60 \\
& & \\
\% used condoms consistentlyt & 65 & 52 \\
With clients & 12 & 14 \\
With emotional partner & 33 & 25 \\
With both partner types & & 32 \\
\% experienced condom breakage in the past 30 dayst & 51 & \\
\% accepted extra money for sex with & & \\
no condom in past 30 days & 28 & 22 \\
\hline
\end{tabular}

* Respondents could specify multiple methods. †During last five sex acts. ₹Refers to husband, boyfriend or other steady partner. Note: $\mathrm{Cl}=$ confidence interval.

the past 30 days, use was far from consistent and differed with the type of partner; it was far more common with clients than with emotional partners. Only 65\% of hotelbased sex workers and $52 \%$ of street-based sex workers reported having used condoms during all of their last five sex acts with clients, and fewer than 15\% of either group reported having used condoms during all of their last five sex acts with emotional partners (Table 2). Other factors also contributed to ineffective or inconsistent condom use. Condom breakage was common, and approximately onefourth of sex workers in each group acknowledged that they had accepted extra money from a client in exchange for not using a condom.

In in-depth interviews, many respondents reported that they always used condoms, although some noted that the condoms sometimes tear. Consistent users were willing to lose a client rather than engage in unprotected sex. As one sex worker explained,

"Okay, sister, money doesn't solve everything. Tell me sister, if you get [a] life threatening disease, then money can't [cure] your disease, [can] it? No, that's why I use condoms.... Those who don't want to use [them], I do not do sex with them."-Street-based sex worker, age 21

Conversely, nearly half of respondents said that they try to persuade clients to use condoms, but are not always successful. They felt that they did not have control over condom use and could not force clients to use one, and many would forego condom use rather than risk losing a client:

"Some clients want to use [a] condom, some do not. I cannot force them. They say, 'Haven't I paid you to come here? If you don't want to have sex without a condom, then go out and I will get some other girl.' I don't have control."-Hotel-based sex worker, age 28

"Now I am getting older. If I want to have every inter- 
TABLE 3. Prevalence of experiences with gender-based violence and beliefs about possible future violence among female sex workers, by location of sex work

\begin{tabular}{|c|c|c|}
\hline Measure & $\begin{array}{l}\text { Hotel } \\
(\mathrm{N}=354)\end{array}$ & $\begin{array}{l}\text { Street } \\
(\mathrm{N}=323)\end{array}$ \\
\hline \multicolumn{3}{|l|}{ EXPERIENCES } \\
\hline \multicolumn{3}{|l|}{ Was injured/beaten in past year by: } \\
\hline Any partner & 43 & 80 \\
\hline Emotional partner* & 39 & 42 \\
\hline Client & 12 & 43 \\
\hline Someone else associated with work & 5 & 19 \\
\hline Police & 2 & 37 \\
\hline Family member & 8 & 9 \\
\hline Was forced to have sex in past year & 28 & 54 \\
\hline \multicolumn{3}{|l|}{ BELIEFS } \\
\hline \multicolumn{3}{|l|}{ If became pregnant, would be beaten by: } \\
\hline Anyone (any response) & 31 & 40 \\
\hline Emotional partner* & 20 & 23 \\
\hline Family member & 18 & 10 \\
\hline Client & 4 & 22 \\
\hline $\begin{array}{l}\text { Would be beaten by client } \\
\text { if insisted on condom use }\end{array}$ & 9 & 28 \\
\hline $\begin{array}{l}\text { Would be beaten by someone else associated } \\
\text { with work if insisted on condom use with client }\end{array}$ & 2 & 5 \\
\hline $\begin{array}{l}\text { Would be beaten by emotional partner } \\
\text { if insisted on condom use* }\end{array}$ & 9 & 24 \\
\hline
\end{tabular}

*Among respondents with a husband, boyfriend or steady partner (227 hotel-based and 241 street-based respondents). Note: All values are percentages.

course with condoms, I will get only a few customers. Then it will be difficult to maintain my livelihood."-Hotelbased sex worker, age 25

\section{Gender-Based Violence}

Experiences with gender-based violence were common among both groups of sex workers (Table 3). Forty-three percent of hotel-based sex workers reported that they had been injured or beaten in the 12 months prior to the survey; the perpetrators most often were emotional partners, clients or family members. In addition, $28 \%$ had been forced to have sex. Among street-based sex workers, $80 \%$ had received an injury or beating, most frequently from clients, emotional partners, police or people associated with the respondent's sex work, and 54\% had been forced to have sex.

Many respondents believed that they would be beaten if they became pregnant or if they insisted on condom use with a client or emotional partner. About a third of hotelbased sex workers (31\%) thought they would be beaten if they became pregnant; they said that emotional partners and family members were the individuals who would be most likely to beat them. Two-fifths of street-based sex workers (40\%) believed that they would be beaten if they became pregnant; emotional partners and clients were considered the most likely perpetrators. More than one in four thought they would be beaten if they insisted on condom use with a client.

Although participants in the in-depth interviews were not specifically asked about violence, the topic emerged spontaneously in nearly all of the interviews with streetbased sex workers and about half of those with hotelbased sex workers. Together, participants described many types of situations in which they had experienced physical and sexual violence, and some discussed multiple episodes. A few had been employed as domestic workers and raped by a member of the household; they eventually lost their job, which in turn led them to go into sex work. For example, a 25-year-old street-based sex worker had the following experience:

"I came to Dhaka to earn my living. I met one woman who managed [to get] work for me as a house maid.... One night my landlord had sexual intercourse with me forcefully... I came to know that I was pregnant. When my abdomen got heavier, my master [found out] and terminated me from my work."

Nearly half of those who talked about violence described being beaten by clients, and a similar number said they had been beaten by police. One 28-year-old street-based sex worker described her experiences with the police in this way: "As I am working in the streets, I have to face a lot of problems, like police raids. The RAB [law enforcement agency] comes to beat us.... The public also beats us.... We are working here at risk."

Although the police were perpetrators, they were also sometimes clients, as one respondent noted:

"Police, army ... all kinds of people ... come to us. They create a lot of problems. On the one hand, they come to us [to have] sexual intercourse. On the other hand, they lock us up and beat us. After this they come to us again. Just imagine how clever they are."-Hotel-based sex worker, age 27

Participants also described other circumstances in which they had experienced violence. A few said that a client had lured them to a place where they were then raped by several men. Consistent with the survey findings, several mentioned that clients had beaten them for attempting to use condoms, and some reported that hotel staff had beaten them for the same reason:

"I have been beaten by many customer[s] for wishing to use condoms."-Street-based sex worker, age 27

"No, I don't force them [to use condoms].... I don't have the nerve to say 'no.' Otherwise, the supervisor will beat me if clients [complain about] me."-Hotel-based sex worker, age 22

Several women talked about the violence they had experienced at the hands of their husbands. They described having been beaten, scolded, kicked out of the house or "tortured" for a range of reasons, including for wanting to use a condom:

"If I wanted to use [a] condom, then he beat me and said "Why do you want to use [a] condom with me? Am I an outsider? Why should I use it with my wife?"'-Streetbased sex worker, age 21

As a result of these experiences, women not only feared for their safety if they were recognized on the street as sex 


\begin{tabular}{|c|c|c|}
\hline Measure & $\begin{array}{l}\text { Hotel } \\
(\mathrm{N}=354)\end{array}$ & $\begin{array}{l}\text { Street } \\
(\mathrm{N}=323)\end{array}$ \\
\hline \multicolumn{3}{|l|}{ No. of SRH services received in past six months } \\
\hline 0 & 36 & 11 \\
\hline 1 & 39 & 35 \\
\hline 2 & 20 & 33 \\
\hline$\geq 3$ & 5 & 22 \\
\hline \multicolumn{3}{|c|}{ Types of SRH services received in past six months*, $\uparrow$} \\
\hline STI testing/treatment & 77 & 81 \\
\hline Maternal and child health care & 32 & 53 \\
\hline Treatment for injuries from violence & 16 & 31 \\
\hline Menstrual regulation & 13 & 16 \\
\hline Family planning & 8 & 9 \\
\hline \multicolumn{3}{|l|}{ Locations where SRH services obtained*, $\dagger$} \\
\hline Private facility/drug shop & 63 & 29 \\
\hline Drop-in center & 41 & 60 \\
\hline Public facility & 12 & 24 \\
\hline Other NGO facility & 9 & 37 \\
\hline No response & 5 & 1 \\
\hline Discloses sex work to providers $¥$ & 5 & 14 \\
\hline \multicolumn{3}{|l|}{$\begin{array}{l}\text { Change in quality of treatment expected } \\
\text { if disclosed sex work }\end{array}$} \\
\hline Better & 12 & 18 \\
\hline Same & 10 & 7 \\
\hline Worse & 68 & 68 \\
\hline Don't know/no response & 10 & 7 \\
\hline $\begin{array}{l}\text { Knows where to go for family } \\
\text { planning services }\end{array}$ & 48 & 69 \\
\hline \multicolumn{3}{|l|}{$\begin{array}{l}\text { Preferred locations for receiving future } \\
\text { family planning services }\end{array}$} \\
\hline Drop-in center & 45 & 51 \\
\hline Other NGO facility & 17 & 25 \\
\hline Public facility & 12 & 12 \\
\hline Private facility/drug shop & 16 & 10 \\
\hline Other/no interest in family planning services & 9 & 3 \\
\hline No response & 16 & 11 \\
\hline \multicolumn{3}{|l|}{$\begin{array}{l}\text { Preferred locations for receiving } \\
\text { future general health services§ }\end{array}$} \\
\hline Drop-in center & 38 & 45 \\
\hline Private provider & 44 & 18 \\
\hline
\end{tabular}

*Among respondents who had received services (226 hotel-based and 288 street-based sex workers). †Multiple responses allowed. $¥$ Refers only to providers at facilities other than drop-in centers. §Only the two most common responses are listed. Notes: $\mathrm{SRH}=$ sexual and reproductive health. $\mathrm{NGO}=$ nongovernmental organization.

workers, but also feared insisting on condom use with clients and husbands.

\section{Health Care Experiences and Preferences}

In the previous six months, $64 \%$ of hotel-based female sex workers and $89 \%$ of street-based female sex workers had gone to a provider for at least one of the following services: STI testing and treatment, maternal and child health care, treatment for violence-related injuries, menstrual regulation and family planning (Table 4). Among women who had visited a provider, the service most often used was STI testing and treatment $(77-81 \%$ of women in the two groups), followed by maternal and child health services (32-53\%) and treatment for injuries related to violence
(16-31\%). Hotel-based sex workers who had received services were most likely to have done so at a private provider or drug shop (63\%) or a drop-in center (41\%); among street-based sex workers, the most commonly used venues were drop-in centers (60\%) and facilities run by other NGOs (37\%). The use of public facilities was relatively low in both groups. Very few women reported disclosing that they were sex workers to health care providers (other than those at drop-in centers), and more than two-thirds of women in both groups felt that they would be treated worse by providers if they disclosed their sex work.

Fewer than half of the hotel-based sex workers and about two-thirds of the street-based sex workers indicated that they knew where to go for family planning information and methods. When respondents were asked where they would like to go for future family planning services, the most commonly mentioned venues were drop-in centers, cited by $45 \%$ of hotel-based sex workers and $51 \%$ of street-based sex workers. For the latter group, drop-in centers were also the preferred site for receiving future health services in general.

The preference for drop-in centers was explained in indepth interviews: Although respondents said they attended drop-in centers primarily for STI/HIV services, more than half had received family planning information as well. Most said that they were treated well at the drop-in centers (only one voiced a complaint); as one respondent noted:

"They provide services to us free of cost and behave very well. Besides that, I can share my problems freely with them-that is why I am satisfied."-Hotel-based sex worker, age 26

Furthermore, half of respondents believed that drop-in centers protected their privacy; just one expressed a fear that they did not. A 24-year-old hotel-based sex worker commented, "Here, everybody knows about me. We can tell about our identity easily here. I have faith that anything about my problem will be kept confidential."

\section{DISCUSSION}

We documented a high level of unmet need for contraception among a population of female sex workers who largely wanted to avoid pregnancy in the near future. These women had a compelling desire to avoid pregnancies that presumably would have profound effects on their emotional, physical and financial well-being. ${ }^{22}$ Similar to findings of other studies, ${ }^{6,9,13,14}$ our results point to a need to provide sex workers with information about, and access to, a range of contraceptive methods. Although nearly all of the sex workers in our survey sample used condoms, either alone or in combination with another modern method, their condom use was inconsistent. The high proportion of women who reported having had menstrual regulations and abortions further suggests that their use of contraceptive methods was ineffective. In addition, despite the widespread desire to avoid pregnancy and to use contraceptives, a large proportion of the women did not know where to obtain family planning information or services. 
Our findings on condom use are especially troubling given that inconsistent use places female sex workers at increased risk of not only becoming pregnant, but also acquiring and transmitting STIs, including HIV. The high percentage of study participants who reported needing STI treatment in the past six months underscores the extent of this problem. Many of the reasons that study participants cited for not using condoms indicate that use is often outside of sex workers' control, and that interventions that exclusively target these women are unlikely to be highly effective in increasing use, as many sex workers who suggest using condoms will not be able to withstand threats of-or actual-physical harm. Moreover, most cannot afford to turn away a client who threatens to go to another sex worker who is willing to forgo condom use. Strategies are needed to ensure that men are fully aware of and appreciate the risk of disease acquisition associated with not using condoms.

Another issue is the high rate of condom breakage, though it is unclear why this problem is so common. Other studies have documented high rates of condom breakage among female sex workers and have found that incorrect use, improper fit, rough sex and sex with a paying partner are associated with breakage. ${ }^{6,23,24}$ Both female sex workers and men require education and strategies to help minimize the number of breakages.

In the meantime, female sex workers should not rely on condoms alone for pregnancy prevention, and they should be encouraged to adopt dual method use. ${ }^{8}$ While promotion of methods other than condoms is often a concern in HIV programs, the evidence suggests that individuals at high risk for HIV do not substitute other methods for condoms. ${ }^{2,8,25}$ Our data clearly show that female sex workers recognize the need for condoms for disease prevention, regardless of whether they are using another contraceptive method.

Female sex workers need a wide range of reproductive health services, and participants in our study relied primarily on the private sector (including drug shops) and NGOs when they sought care. The women indicated a preference for services provided by NGOs, and the qualitative data highlight the level of trust and comfort they had with these services. This is consistent with previous evidence suggesting that female sex workers prefer receiving services at sites separate from the general population, ${ }^{5}$ although a recent study in Kenya showed that while female sex workers preferred to go to drop-in centers for services, they were concerned about the stigma associated with using a facility that targeted them. ${ }^{26}$ Drop-in centers in Dhaka already provide family planning services, and further integration with existing STI/HIV services should be feasible, though some additional training may be needed, especially to expand the range of methods available on site. Provision of a wider range of methods will require that policies that deny unmarried women access to contraceptives be changed; the recent elimination of the requirement that implant users already have a child is an encouraging step. ${ }^{21}$ While it may be tempting to try to meet all of the sexual and reproductive health service needs of female sex workers at a single site, we must bear in mind that integration can present logistical and other challenges, such as ensuring adequate staffing, training and space and maintaining quality of services. ${ }^{2,5}$

One pressing need that stands out is that for services and interventions that address gender-based violence. Levels of such violence are high in Bangladeshi society in general, and are particularly high among female sex workers. The 2007 Demographic Health Survey, which included a special module on gender-based violence, found that nearly half of ever-married women had experienced some form of physical violence from their current or former husband. In addition, nearly one-fifth had been physically forced to have sex. ${ }^{27}$ Our study, which assessed physical and sexual violence in the past 12 months, found even higher rates. The qualitative data highlight the extent of the violence and the most common perpetrators. The need to provide outreach, linkages and referrals to services and organizations addressing this issue is critical to the well-being of these women. Furthermore, structural interventions that reduce the prevalence of violence against them are called for.

One limitation of this study is that we fell somewhat short of our target sample size for the survey, and met only the minimum target for in-depth interviews. This was due to events that hindered data collection, such as police raids, hotel closings, strikes and monsoons. In addition, our survey sample did not include sex workers who started work later in the evening and may have missed women who were present at hotels or street sites infrequently; these women may have needs that differ from those reported here. Similarly, we missed female sex workers who attended drop-in centers at hours or on days different from those when the in-depth interviews took place. We also missed sex workers who did not attend drop-in centers or who had stopped attending because of dissatisfaction with services, which could have affected our results on service quality. Despite this, we believe we obtained sufficient data from the combination of the survey and in-depth interviews to meet our objectives and provide valuable information to our NGO partners and other stakeholders for programmatic decision making. We should also note that the calculation used for unmet need is not directly comparable with the calculations from other studies, as the definitions and measurements of fertility desires, method use and consistency of condom use vary among studies., ${ }^{9}, 10,14$ As we explained earlier, our measure of unmet need used definitions of fertility desires and consistent condom use that were stricter than those typically used in other studies.

This study demonstrated that female sex workers in Dhaka have pressing sexual and reproductive health needs, including a need for information on, and access to, a range of contraceptive methods, as well as for interventions that will help them use condoms consistently and reduce the level of gender-based violence in their lives. 
Expansion of services by the drop-in centers was a needed first step, one that can be enhanced through strengthened integration efforts, linkages to other needed services and changes in restrictive policies. Further research is needed to examine costs, utilization and long-term sustainability of different models of service delivery targeting female sex workers, though researchers, policymakers and other stakeholders should keep in mind that service preferences may vary across settings.

\section{REFERENCES}

1. Becker M et al., The intersection between sex work and reproductive health in Northern Karnataka, India: identifying gaps and opportunities in the context of HIV prevention, AIDS Research and Treatment, 2012, Art. 842576, doi: 10.1155/2012/842576.

2. Petruney $T$ et al., Meeting the contraceptive needs of key populations affected by HIV in Asia: an unfinished agenda, AIDS Research and Treatment, 2012, Art. 792649, doi: $10.1155 / 2012 / 792649$

3. Wayal $S$ et al., Contraceptive practices, sexual and reproductive health needs of HIV-positive and negative female sex workers in Goa, India, Sexually Transmitted Infections, 2011, 87(1):58-64.

4. Chacham AS et al., Sexual and reproductive health needs of sex workers: two feminist projects in Brazil, Reproductive Health Matters, 2007, 15(29):108-118.

5. Lafort Y et al., Reproductive health services for populations at high risk of HIV: performance of a night clinic in Tete province, Mozambique, BMC Health Services Research, 2010, Vol. 10, Art. 144, doi: 10.1186/1472-6963-10-144

6. Morineau $G$ et al., Falling through the cracks: contraceptive needs of female sex workers in Cambodia and Laos, Contraception, 2011, 84(2):194-198

7. Lau JTF et al., Prevalence of induced abortion and associated factors among Chinese female sex workers in Hong Kong, Journal of Sex \& Marital Therapy, 2007, 33(1):19-29.

8. Feldblum PJ et al., Pregnancy among sex workers participating in a condom intervention trial highlights the need for dual protection, Contraception, 2007, 76(2): 105-110.

9. Khan MR et al., Unmet need for contraception among sex workers in Madagascar, Contraception, 2009, 79(3):221-227.

10. Sutherland EG et al., Contraceptive needs of female sex workers in Kenya-a cross-sectional study, European Journal of Contraception $\&$ Reproductive Health Care, 2011, 16(3):173-182.

11. National AIDS/STD Programme (NASP), Save the Children USA and International Centre for Diarrhoeal Disease Research, Bangladesh (ICDDR,B), Understanding the Operational Dynamics and Possible HIV Interventions for Residence-Based Female Sex Workers in Two Divisional Cities in Bangladesh, Dhaka, Bangladesh: NASP, Save the Children USA and ICDDR,B, 2009

12. Elmore-Meegan M, Conroy RM and Agala CB, Sex workers in Kenya, numbers of clients and associated risks: an exploratory survey, Reproductive Health Matters, 2004, 12(23):50-57.

13. Delvaux $\mathrm{T}$ et al., The need for family planning and safe abortion services among women sex workers seeking STI care in Cambodia, Reproductive Health Matters, 2003, 11(21):88-95.

14. Todd CS et al., Contraceptive utilization and pregnancy termination among female sex workers in Afghanistan, Journal of Women's Health, 2010, 19(11):2057-2062.

15. Bautista CT et al., Prevalence of lifetime abortion and methods of contraception among female sex workers in Bogota, Colombia, Contraception, 2008, 77(3):209-213.

16. Goodwin J, Sex Work and the Law in Asia and the Pacific, Bangkok: United Nations Development Programme, 2012.

17. NASP, Directorate General of Health Services (DGHS) and
Ministry of Health and Family Welfare (MOHFW), Behavioral Surveillance Survey 2006-2007, Technical Report, Dhaka, Bangladesh: NASP, DGHS and MOHFW, 2008

18. Karim R, Selim N and Rashid SF, Sex workers and condom usethe political economy of HIV/AIDS in Bangladesh, Working Paper, Dhaka, Bangladesh: Research and Evaluation Division, BRAC, 2008, No. 4.

19. Huq NL and Chowdhury ME, Assessment of utilization of HIV interventions by sex workers in selected brothels in Bangladesh: an exploratory study, Qualitative Report, 2012, Vol. 17, Art. 38, http:// www.nova.edu/ssss/QR/QR17/huq.pdf.

20. FHI 360, Modhumita: An integrated approach to service delivery, 2012, http://www.fhi360.org/news/modhumita-integrated-approachservice-delivery.

21. The RESPOND Project, Achieving positive policy changes for family planning in Bangladesh, RESPOND Project Brief, New York: EngenderHealth, 2012, No. 8.

22. Katz KR et al., "I won't be able to go home pregnant": sex work and pregnancy in Dhaka, Bangladesh, Culture, Health \& Sexuality, 2016 (forthcoming).

23. Bradley J et al., Why do condoms break? A study of female sex workers in Bangalore, South India, Sexually Transmitted Infections, 2012, 88(3):163-170.

24. Mukenge-Tshibaka L et al., Incorrect condom use and frequent breakage among female sex workers and their clients, International Journal of STD \& AIDS, 2005, 16(5):345-347.

25. Baumgartner JN et al., Integrating family planning services into HIV care and treatment clinics in Tanzania: evaluation of a facilitated referral model, Health Policy and Planning, 2014, 29(5):570-579.

26. Dulli L et al., Formative research to design an intervention to increase contraceptive and dual method use among female sex workers in Kenya, paper presented at International Conference on Family Planning, Addis Ababa, Ethiopia, Nov.12-15, 2013.

27. National Institute of Population Research and Training (NIPORT), Mitra and Associates, and Macro International, Bangladesh Demographic and Health Survey 2007, Calverton, MD, USA: NIPORT, Mitra and Associates, and Macro International, 2009.

\section{RESUMEN}

Contexto: Se sabe poco acerca de las necesidades de salud sexual y reproductiva de las trabajadoras sexuales en Daca, Bangladés.

Métodos: Se recolectaron datos de encuestas a 354 trabajadoras sexuales que trabajan en hoteles y 323 que trabajan en la calle, usando un muestreo estratificado por conglomerado basado en el punto de encuentro. Además, se condujeron 20 entrevistas en profundidad con trabajadoras sexuales reclutadas en centros de acogida. Se calculó la necesidad insatisfecha de planificación familiar y se realizaron análisis que examinaron los deseos de fecundidad, el uso de condones y otros métodos anticonceptivos, las experiencias con violencia basada en género, las necesidades de servicios de salud sexual y reproductiva, así como las preferencias acerca del lugar en donde recibir los servicios.

Resultados: La prevalencia de la necesidad insatisfecha fue de $25 \%$ entre las trabajadoras sexuales que trabajan en hoteles $y$ de $36 \%$ entre las que trabajan en la calle. Casi todas las participantes reportaron haber usado condones en los pasados 30 dias; $44 \%$ de las que trabajan en hoteles y 30\% de las que lo hacen en la calle reportaron el uso de doble protección durante ese período. Sin embargo, el uso del condón fue inconsistente y fueron comunes las roturas y la falta de uso debido al costo 
adicional. Muchas mujeres reportaron estar experimentando violencia basada en género. El 64\% de las trabajadoras sexuales que trabajan en hoteles y el $89 \%$ de las que trabajan en la calle habian obtenido servicios de salud sexual y reproductiva en los pasados seis meses; los centros de acogida fueron los sitios preferidos para recibir servicios sanitarios.

Conclusiones: Las trabajadoras sexuales en Daca necesitan servicios de planificación familiar y otros servicios de salud sexual y reproductiva, y prefieren recibirlos en centros de acogida.

\section{RÉSUMÉ}

Contexte: Les besoins de soins de santé sexuelle et reproductive des travailleuses du sexe de Dhaka (Bangladesh) ne sont guère documentés.

Méthodes: Les données d'enquête ont été collectées auprès de 354 et 323 travailleuses du sexe en hôtel et de rue, respectivement, selon une approche d'échantillonnage en grappes stratifié suivant le lieu. Des entretiens en profondeur ont également été menés avec 20 travailleuses du sexe recrutées dans les centres d'accueil. Le besoin non satisfait de planification familiale a été calculé et les analyses ont examiné les désirs de fécondité, l'usage du préservatif et d'autres méthodes contraceptives, l'expérience de la violence basée sur le genre, les besoins de services de santé sexuelle et reproductive et les préférences concernant la source de ces services.

Résultats: La prévalence du besoin non satisfait s'est révélée de $25 \%$ et $36 \%$, respectivement, parmi les travailleuses du sexe en hôtel et de rue. Presque toutes les participantes ont déclaré avoir utilisé le préservatif durant les 30 derniers jours écoulés, tandis que 44\% des travailleuses en hôtel et 30\% de celles de rue faisaient état de méthodes doubles durant cette même période. L'usage du préservatif est cependant irrégulier et la rupture ou le non-usage à prix supplémentaire sont fréquents. La violence basée sur le genre est déclarée par de nombreuses femmes. Soixante-quatre pour cent des travailleuses en hôtel et $89 \%$ de celles de rue avaient obtenu des services de santé sexuelle et reproductive durant les six derniers mois. Les centres d'accueil sont leur lieu de prédilection pour l'obtention de ces services.

Conclusions: Les travailleuses du sexe de Dhaka présentent un besoin de planification familiale et d'autres services de santé sexuelle et reproductive. Elles préfèrent obtenir ces services dans les centres d'accueil.

Author contact: kkatz@fhi360.org 